\title{
The influence of atorvastatin on parameters of inflammation left ventricular function, hospitalizations and mortality in patients with dilated cardiomyopathy - 5-year follow-up
}

\author{
Agata Bielecka-Dabrowa ${ }^{1 *}$, Dimitri P Mikhailidis ${ }^{2}$, Manfredi Rizzo ${ }^{3,4}$, Stephan von Haehling ${ }^{5}$,
} Jacek Rysz ${ }^{6}$ and Maciej Banach ${ }^{1^{*}}$

\begin{abstract}
Background: We assessed the influence of atorvastatin on selected indicators of an inflammatory condition, left ventricular function, hospitalizations and mortality in patients with dilated cardiomyopathy (DCM).

Methods: We included 68 DCM patients with left ventricular ejection fraction (LVEF) $\leq 40 \%$ treated optimally in a prospective, randomized study. They were observed for 5 years. Patients were divided into two groups: patients who were commenced on atorvastatin $40 \mathrm{mg}$ daily for two months followed by an individually matched dose of 10 or $20 \mathrm{mg} /$ day (group A), and patients who were treated according to current recommendations without statin therapy (group B).
\end{abstract}

Results: After 5-year follow-up we assessed 45 patients of mean age $59 \pm 11$ years - 22 patients in group A (77\% male) and 23 patients in group B (82\% male). Interleukin-6, tumor necrosis factor alpha, and uric acid concentrations were significantly lower in the statin group than in group $B(14.96 \pm 4.76$ vs. $19.02 \pm 3.94 \mathrm{pg} / \mathrm{ml}, p=0.012 ; 19.10 \pm 6.39$ vs. $27.53 \pm 7.39 \mathrm{pg} / \mathrm{ml}, p=0.001$, and $5.28 \pm 0.48 \mathrm{vs}$. $6.53 \pm 0.46 \mathrm{mg} / \mathrm{dl}, p=0.001$, respectively). In patients on statin therapy a reduction of $\mathrm{N}$-terminal pro-brain natriuretic peptide concentration (from $1425.28 \pm 1264.48$ to $1098.01 \pm 1483.86 \mathrm{pg} / \mathrm{ml}$, $p=0.045$ ), decrease in left ventricular diastolic (from $7.15 \pm 0.90$ to $6.67 \pm 0.88 \mathrm{~cm}, p=0.001$ ) and systolic diameters (from $5.87 \pm 0.92$ to $5.17 \pm 0.97, p=0.001$ ) in comparison to initial values were observed. We also showed the significant increase of LVEF in patients after statin therapy (from $32.0 \pm 6.4$ to $38.8 \pm 8.8 \%, p=0.016$ ). Based on a comparison of curves using the log-rank test, the probability of survival to 5 years was significantly higher in patients receiving statins $(p=0.005)$.

Conclusions: Atorvastatin in a small dose significantly reduce levels of inflammatory cytokines and uric acid, improve hemodynamic parameters and improve 5-year survival in patients with DCM.

Keywords: Atorvastatin, Dilated cardiomyopathy, Heart failure, Inflammation

\section{Introduction}

According to the European Society of Cardiology (ESC), dilated cardiomyopathy (DCM) is recognized based on dilation and systolic dysfunction of the left ventricle, unless a patient simultaneously suffers from coronary artery disease $(\mathrm{CAD})$, hypertension, valvular heart disease

\footnotetext{
* Correspondence: agatbiel7@poczta.onet.pl; maciejbanach@aol.co.uk ${ }^{1}$ Department of Hypertension, Chair of Nephrology and Hypertension, Medical University of Lodz, Lodz, Poland

Full list of author information is available at the end of the article
}

or congenital heart disease which is so significant that it leads to an observed pathology of the myocardium [1].

DCM occurs more frequently in men and is most common between the ages of 20 and 60 years $[1,2]$. About 1 in 3 cases of congestive heart failure (CHF) is due to DCM. Despite treatment, CHF is a progressive disease with high morbidity and mortality, suggesting that important pathogenic mechanisms remain active and unmodified by currently available treatment $[1,2]$.

The cause of mortality in these patients is either endorgan dysfunction due to pump failure or arrhythmia- 
related death $[3,4]$. Within recent years more and more evidence has been presented indicating that autoimmunologic processes, cellular as well as humoral ones, are involved in the pathogenesis of dilated cardiomyopathy [3]. The common presence of viral genetic material in the myocardium of patients with DCM provides the most compelling evidence, but proof of causality is still lacking [3,4]. In addition, autoimmune reactions have been described in many studies, indicating them as an important etiologic factor $[3,4]$. A pivotal role for autoimmunity in a substantial proportion of patients with DCM is supported by the presence of organ-specific autoantibodies, inflammatory infiltrates and pro-inflammatory cytotoxic cytokines [3-6]. Furthermore, familial occurrence of DCM has been described in about $20-30 \%$ of cases, with the presence of autoantibodies and abnormal cytokine profiles in first-degree relatives with asymptomatic left ventricular enlargement [3,4]. This suggests the involvement of a disrupted humoral and cellular immunity early in the development of the disease $[3,4]$.

Despite their lipid-lowering and anti-atherosclerotic effects statins have also important pleiotropic properties. They limit signal transmission from membrane receptors and slow down pathologic remodeling of the heart and vessels, inhibit the action of angiotensin II, inhibit apoptosis, improve endothelial function, retard the progression of heart failure symptoms, reduce the level of N-terminal pro-brain natriuretic peptide (NT-proBNP), restore autonomic nervous system balance and might have a protective influence on renal function and blood pressure $[7,8]$. Previous studies have demonstrated that statins reduce vascular and myocardial oxidative stress by inhibiting Racinduced nicotinamide adenine dinucleotide phosphatase (NADPH) oxidase activity and reducing oxidized low density lipoprotein (LDL) concentration by activated monocyte-derived macrophages [9]. They also reduce intracellular reactive oxygen species (ROS) in endothelial cells by S-nitrosylation of thioredoxin $[9,10]$.

The Rosuvastatin Impact on Ventricular Remodelling Lipids and Cytokines (UNIVERSE), Controlled Rosuvastatin Multinational Trial in Heart Failure (CORONA), and Effect of rosuvastatin in patients with chronic heart failure (GISSI-HF) trials did not indicate a significant role for statins in HF patients, although the drug did reduce the number of cardiovascular (CV) hospitalizations in the CORONA trial [11-13]. Although mentioned prospective studies using hydrophilic rosuvastatin showed no beneficial effect on mortality, Vrtovec et al. reported that atorvastatin therapy reduced the incidence of sudden cardiac death in patients with advanced CHF [14]. Correale et al. evaluated the effect of statin therapy on left ventricular dysfunction in patients with CHF and showed that they had fewer readmissions for adverse events, blunted inflammatory activation and improved left ventricular performance assessed by tissue Doppler imaging [15]. Metabolic and cardiac effects may differ between the lipophilic and hydrophilic statins [16].

Therefore the aim of our study was to assess the association between 5 -year atorvastatin therapy and indicators of an inflammatory condition and clinical outcomes in patients with DCM.

\section{Methods}

\section{Study population}

In a prospective study, 68 patients with DCM (according to the 2008 European Society of Cardiology [ESC] classification) of either sex, aged 18 years or older with left ventricular ejection fraction (LVEF) $\leq 40 \%$ treated with optimal medical therapy, were followed for 5 years $[17,18]$. Mean disease duration was $7.5 \pm 1.9$ years. No patients had significant coronary artery disease (>30\% stenosis) as determined by cardiac catheterization performed within a year before the enrolment $[19,20]$. Arterial hypertension was not diagnosed in any of the patients. Date of death was ascertained by questioning relatives or patients' general practitioners and estimated as close as possible to half year frames. Patients were randomized to one of two groups: A - patients who were commenced on atorvastatin $40 \mathrm{mg}$ daily for 2 months followed by an individually matched dose of 10 or $20 \mathrm{mg} /$ day; and B - patients who were treated according to current guidelines [21] without statin therapy.

The exclusion criteria were as follows: blood pressure (BP) $\geq 140 / 90$ or $<90 / 60 \mathrm{mmHg}$; congenital heart disease; acquired valvular disease with the exception of mitral incompetence secondary to left ventricular dilatation; persistent hyperactivity of aminotransferases with an unexplained etiology; muscle disorders which might cause druginduced myopathy; uncontrolled diabetes; liver diseases, creatinine level $>2 \mathrm{mg} / \mathrm{dl}$ and/or glomerular filtration rate (GFR) $<30 \mathrm{ml} / \mathrm{min}$; alcohol or drug abuse; chronic inflammatory diseases, pregnancy or lactation, severe hypothyroidism, immunosuppressive treatment, operation or severe injury during the month prior to blood collection, and patients who did not provide written informed consent.

Initial and control tests included full clinical examination with the assessment of body mass index (BMI) and New York Heart Association (NYHA) class, routine laboratory tests, measurement of TNF- $\alpha$, interleukin 6 (IL-6), and transforming growth factor beta (TGF- $\beta$ ) concentrations in blood plasma, measurement of N-terminal pro-brain natriuretic peptide (NT-proBNP), syndecan-4, cystatin C (CysC) concentration in blood serum, echocardiographic examination and the assessment of exercise capacity in 6-min walk test (6MWT). The frequency of $\mathrm{HF}$ hospitalization and mortality were recorded during the 5-year follow-up period.

Consent from the Bioethics Commission of the Medical University of Lodz (No. RNN/520/10/KB) was obtained. Written informed consent was obtained from all the patients. 


\section{Biochemical tests}

Blood glucose was measured with a glucose dehydrogenase method after precipitation of proteins by trichloroacetic acid. LDL and high-density lipoprotein (HDL) fractions were separated from fresh serum by combined ultracentrifugation and precipitation. Lipoprotein fraction cholesterol and triglycerides were measured enzymatically. The concentration of NT-proBNP was determined using an Elecsys 2010 analyzer (Roche Diagnostics, Warsaw, Poland). After the blood was taken, the material was centrifuged; the obtained serum was frozen at the temperature of $-70^{\circ} \mathrm{C}$ and stored in this condition until the time of examination.

The determination of NT-proBNP in blood serum was performed with the electroluminescence method with 2 polyclonal antibodies directed against NT-proBNP within epitope 1 (1-21 amino acid sequence) and epitope 2 (3950 amino acids). Concentration values are given in $\mathrm{pg} / \mathrm{ml}$. Determination of IL- 6 and TNF- $\alpha$ was performed with reagents of Beckman Coulter (Paris, France), using a sandwich ELISA assay. Measurement of CysC was performed using immunonephelometric assay for the quantitative measurement of this marker in human serum and heparinized plasma. Diazyme's Cystatin $\mathrm{C}$ assay is based on the latex-enhanced immunoturbidimetric method. The range of valid values for CysC measured by the immunonephelometric method ( $\mathrm{N}$ Latex Cystatin $\mathrm{C}$ test) is 0.53$0.95 \mathrm{mg} / \mathrm{l}$. Determination of syndecan 4 was performed with reagents of USCN Life Science Inc. (Wuhan, China), using a sandwich ELISA assay [19]. Determination of TGF- $\beta$ was performed with reagents of Diaclone/GenProbe (San Diego, USA), using an enzyme-linked immunosorbent assay.

\section{Echocardiographic assessment}

Echocardiography was performed using an ALOKA Alpha 6 Premier (Tokyo, Japan) with a 3-11 MHz probe. Left ventricular (LV) systolic function and cardiac dimensions indexed to body surface area were determined. The heart was imaged in parasternal short axis view to obtain LV wall thickness and parasternal long axis view to measure ejection fraction (EF), which was determined with Simpson's rule: $E F=(L V E D V-L V E S V) / L V E D V$, where LVEDV is left ventricular end-diastolic volume and LVESV is left ventricular end-systolic volume.

Left ventricular end-diastolic diameter (LVEDD) and left ventricular end-systolic diameter (LVESD) were measured from M-mode tracings. Flow parameters were assessed in Doppler examination (continuous, pulsatile and color). Quantification of LV systolic function was also made through application of:

A. The myocardial performance index (MPI), which reflects global efficiency of LV functioning. It is determined by dividing the sum of isovolumetric relaxation time and isovolumetric contraction time by ejection time. The time of isovolumetric contraction is measured from the closure of the mitral valve to the opening of the aortic valve. The time of isovolumetric relaxation is measured from the closure of the aortic valve to the opening of the mitral valve. The norm is $\leq 0.4$; higher values indicate deteriorating efficiency of the myocardium [20].

B. Rate of systolic pressure change in the left ventricle $(\mathrm{dP} / \mathrm{dT})$. This index determines the increase in systolic pressure generated by the LV in time calculated using continuous wave (CW) Doppler based on the time of increase in the speed of mitral regurgitation (MR) from 1 to $3 \mathrm{~m} / \mathrm{s}$. Values of $\mathrm{dP} / \mathrm{dT}$ $<400 \mathrm{mmHg} / \mathrm{s}$ indicate that the systolic function of the LV is significantly impaired; normal values are $>2000 \mathrm{mmHg} / \mathrm{s}[20,22]$.

Diastolic function of the LV was assessed using the parameters of mitral inflow registered with pulsed wave (PW) Doppler in 4-cavity apical projection and diastolic speed values of movement of the mitral ring registered with tissue Doppler imaging.

\section{Statistical analysis}

The STATISTICA software package 9 (StatSoft, Poland) was used for analysis. All values presented are the mean or median \pm standard deviation (SD) for continuous variables and the percentage of total patients for categorical variables. The Shapiro-Wilk test was used to assess the normality of distribution. To compare groups Student's $t$ test or 2-way analysis of variance (ANOVA) for continuous and discrete variables with normal distribution and non-parametric Mann-Whitney $U$ test if the distribution was not normal were applied. For categorical variables chi-square test or Fisher's test for small samples was applied for comparisons. For quantitative variables (continuous and discrete) to check correlations between variables Spearman's rank correlation coefficient was used. The assessment of factors influencing prognosis in patients with DCM was performed using single-factor logistic regression and the forward stepwise regression model, and receiver operating characteristic (ROC) curves and the forward stepwise regression model. Based on analysis of the ROC curve, cut-off points were found for the measurable variables by estimating the highest product of sensitivity and specificity. Calculations and drawings were made using SPSS 17.0 statistical package. The analysis of death was plotted using the Kaplan-Meier method. Date of death was ascertained by questioning relatives or patients' general practitioners and estimated as close as possible to half year frames. Results were considered significant at $\mathrm{p}<0.05$. 


\section{Results}

\section{Baseline characteristics of the patients}

During 5-year observation 29\% $(n=20)$ of all 68 patients died, $41 \%(n=28)$ required one re-hospitalization and $6 \%(n=4)$ two re-hospitalizations because of HF decompensation. In $9 \%(n=6)$ cardiac resynchronization therapy was applied, mitral and tricuspid valvuloplasty was performed in 1 person and heart transplantation in 2 people (these patients were excluded from the analysis to avoid the imposition of the effect of statins and the results of such procedures).

Finally after 5 years we assessed 45 patients of mean age $59 \pm 11$ years ( 5 females and 40 males): group $A-22$ patients $(77 \%$ male) of mean age $63 \pm 10$ years treated with atorvastatin in individual dose of $10(n=11)$ or $20 \mathrm{mg}(\mathrm{n}=11)$, and group $\mathrm{B}-23$ patients $(82 \%$ male) of mean age $57 \pm 13$ years without statin therapy. In $36 \%$ $(\mathrm{n}=16)$ of patients we observed dyspnea, pulmonary hemostasis in 11\% ( $n=5)$, and edema in 9\% $(n=4)$. Body mass assessment revealed underweight in $4 \%(n=2)$ of patients, normal weight in $36 \%(n=16)$, overweight in $24 \%(n=11)$ and obesity in $36 \%(n=16)$. Chronic obstructive pulmonary disease was present in $4 \%(n=2)$ and diabetes mellitus (DM) or abnormal glucose level in $20 \%(n=9)$ of patients. The detailed characteristics of the patients are presented in Table 1.

\section{The influence atorvastatin treatment on inflammatory} and clinical parameters

In group A compared to group B, IL-6 concentration was considerably lower $(14.96 \pm 4.76$ vs $19.02 \pm 3.94 \mathrm{pg} / \mathrm{ml}$, $p=0.011)$ after five years of treatment with atorvastatin. TNF- $\alpha$ levels were also significantly reduced in the statin group than in Group B $(19.10 \pm 6.39$ vs $27.53 \pm 7.39 \mathrm{pg} / \mathrm{ml}$, $p=0.001$ ). Also uric acid (UA) concentration was lower in the atorvastatin group $(5.28 \pm 0.48 v s 6.53 \pm 0.46 \mathrm{mg} / \mathrm{dl}$, $p=0.001)$. No significant differences concerning NTproBNP concentration, echocardiographic parameters of the left ventricle, distance on 6MWT and in functional classification according to NYHA were observed between examined groups. The detailed comparison between groups $\mathrm{A}$ and $\mathrm{B}$ is presented in Table 2.

\section{Patients with and without atorvastatin therapy - comparing changes over time}

In the statin group after 5 years a decrease in NTproBNP concentration compared with initial values from $1425.28 \pm 1264.48$ to $1098.01 \pm 1483.86 \mathrm{pg} / \mathrm{ml}(p=0.045)$ and a decrease in LVdD and LVsD from $7.15 \pm 0.90$ to $6.67 \pm 0.88 \mathrm{~cm}(p=0.001)$ and from $5.87 \pm 0.92$ to $5.17 \pm$ $0.97(p=0.001)$, respectively, were achieved. The significant increase of LVEF from $32.0 \pm 6.4$ to $38.8 \pm 8.8 \%$ ( $p=$ 0.0164 ) was also observed in Group A. There were no significant changes in the range of these parameters in
Table 1 Characteristics of the analyzed patients with DCM after 5 years

\begin{tabular}{|c|c|}
\hline PARAMETER & Mean \pm SD or number of patients $(\%)$ \\
\hline Age (years) & $59.0 \pm 11.0$ \\
\hline Gender (male) & $40(89)$ \\
\hline \multicolumn{2}{|l|}{ NYHA class } \\
\hline । & $4(9)$ \\
\hline$\|$ & $22(49)$ \\
\hline III & $15(33)$ \\
\hline IV & $4(9)$ \\
\hline Atrial fibrillation & $15(33)$ \\
\hline Hypercholesterolemia & $20(46)$ \\
\hline Anemia* & $4(9)$ \\
\hline $\begin{array}{l}\text { Diabetes mellitus or } \\
\text { abnormal glucose level }\end{array}$ & $9(20)$ \\
\hline LV diastolic dysfunction & $4(9)$ \\
\hline sPAP $>40 \mathrm{mmHg}$ & $4(9)$ \\
\hline \multicolumn{2}{|l|}{ MR degree } \\
\hline 0 & $7(15)$ \\
\hline । & $19(43)$ \\
\hline$\|$ & $15(34)$ \\
\hline III & $4(9)$ \\
\hline \multicolumn{2}{|l|}{ TR degree } \\
\hline 0 & $23(51)$ \\
\hline । & $14(32)$ \\
\hline$\|$ & $8(17)$ \\
\hline \multicolumn{2}{|c|}{ PHARMACOLOGICAL TREATMENT } \\
\hline Loop diuretics & $41(91)$ \\
\hline Spironolactone/eplerenone & $39(87)$ \\
\hline vBeta-blockers & $40(88)$ \\
\hline ACE inhibitors & $41(91)$ \\
\hline Sartans (ARBs) & $4(9)$ \\
\hline Digoxin & $15(34)$ \\
\hline Acenocoumarol/warfarin & $9(20)$ \\
\hline Amiodarone & $4(8)$ \\
\hline Statins & $22(49)$ \\
\hline Insulin & $2(4)$ \\
\hline Oral hypoglycemics & $4(9)$ \\
\hline
\end{tabular}

*Anemia: $\mathrm{Hb}(\mathrm{g} / \mathrm{dL})<13$ in men and $<12$ in women.

ABBREVIATIONS: $A C E$ inhibitors - angiotensin converting enzyme inhibitors;

$A R B$ angiotensin receptor blocker; $M R$ mitral regurgitation; NYHA New York

heart association; $S P A P$ systolic pulmonary artery pressure; $T R$

tricuspid regurgitation.

Group B. Only in the atorvastatin group a significant reductions of total cholesterol (from $207 \pm 71$ to $183 \pm$ $69 \mathrm{mg} / \mathrm{dL}$ ) and LDL cholesterol (from $116 \pm 36$ to $80 \pm$ $25 \mathrm{mg} / \mathrm{dL}$ ) were observed.

In the control group a significant increase in TNF- $\alpha$ levels from $12.70 \pm 12.78$ to $27.50 \pm 7.39 \mathrm{pg} / \mathrm{ml}(p=0.006)$ and an increase in body mass index (BMI) from $29.6 \pm 4.5$ to $31.0 \pm 4.4(p=0.033)$ were found. 
Table 2 Comparison of selected parameters in patients with DCM from group A (atorvastatin group) and group B (without statin) after 5-year follow-up

\begin{tabular}{|c|c|c|c|}
\hline \multirow[t]{2}{*}{ PARAMETER } & Group A $(n=22)$ & Group B $(n=23)$ & $p$ \\
\hline & Mean \pm SD & Mean \pm SD & \\
\hline BMl & $28.9 \pm 4.3$ & $31.0 \pm 4.4$ & $n s^{*}$ \\
\hline Waist circumference $(\mathrm{cm})$ & $98.3 \pm 12.9$ & $96.9 \pm 13.5$ & ns \\
\hline Systolic RR (mm Hg) & $114.7 \pm 13.0$ & $117.5 \pm 7.7$ & ns \\
\hline Diastolic RR (mm Hg) & $71.5 \pm 7.7$ & $77.3 \pm 5.3$ & ns \\
\hline Heart rate & $77 \pm 9$ & $69 \pm 4$ & ns \\
\hline \multicolumn{4}{|l|}{ Biochemical parameters } \\
\hline White blood cells $\left({ }^{*} 10^{3} / \mu \mathrm{l}\right)$ & $6.9 \pm 1.4$ & $7.3 \pm 1.4$ & ns \\
\hline Hemoglobin (g/dl) & $14.6 \pm 1.4$ & $14.5 \pm 1.3$ & ns \\
\hline $\mathrm{Na}(\mathrm{mmol} / \mathrm{l})$ & $138 \pm 4$ & $138 \pm 3$ & ns \\
\hline $\mathrm{K}(\mathrm{mmol} / \mathrm{l})$ & $4.4 \pm 0.4$ & $4.5 \pm 0.5$ & ns \\
\hline Total cholesterol (mg/dl) & $178 \pm 69$ & $202 \pm 30$ & 0.02 \\
\hline HDL cholesterol (mg/dl) & $52 \pm 18$ & $48 \pm 9$ & ns \\
\hline LDL cholesterol (mg/dl) & $78 \pm 25$ & $123 \pm 27$ & 0.001 \\
\hline Triglycerides (mg/dl) & $201 \pm 212$ & $153 \pm 37$ & ns \\
\hline ASPAT (U/I) & $23.6 \pm 6.3$ & $26.2 \pm 9.6$ & ns \\
\hline ALAT (U/I) & $23.5 \pm 7.4$ & $26.3 \pm 10.7$ & ns \\
\hline Urea $(\mathrm{mg} / \mathrm{dl})$ & $30.80 \pm 14.00$ & $39.33 \pm 7.84$ & ns \\
\hline Creatinine (mg/dl) & $0.92 \pm 0.27$ & $1.00 \pm 0.32$ & ns \\
\hline Uric acid (mg/dl) & $5.28 \pm 0.48$ & $6.53 \pm 0.46$ & 0.001 \\
\hline CRP (mg/l) & $1.4 \pm 1.1$ & $2.7 \pm 2.5$ & ns \\
\hline GRF MDRD (ml/min) & $792 \pm 22$ & $71 \pm 19$ & ns \\
\hline
\end{tabular}

\section{Biomarkers}

\begin{tabular}{|c|c|c|c|}
\hline NT-proBNP (pg/ml) & $1098.00 \pm 1483.86$ & $1151.24 \pm 1371.00$ & ns \\
\hline TNF-alpha (pg/ml) & $19.10 \pm 6.40$ & $27.53 \pm 7.39$ & 0.001 \\
\hline Interleukin 6 (pg/ml) & $14.90 \pm 4.70$ & $19.00 \pm 3.94$ & 0.01 \\
\hline Syndecan 4 (ng/ml) & $4.40 \pm 3.10$ & $5.21 \pm 4.00$ & ns \\
\hline Cystatin C (mg/l) & $1.17 \pm 0.39$ & $1.00 \pm 0.18$ & ns \\
\hline TGF-beta (pg/ml) & $470.19 \pm 166.50$ & $463.00 \pm 156.78$ & ns \\
\hline \multicolumn{4}{|c|}{ Echocardiographic parameters } \\
\hline $\mathrm{LVdD}(\mathrm{cm})$ & $6.6 \pm 0.8$ & $6.4 \pm 1.8$ & ns \\
\hline LVsD (cm) & $5.1 \pm 0.9$ & $5.1 \pm 1$ & ns \\
\hline LVEF (\%) & $38.4 \pm 8.8$ & $33.9 \pm 11.5$ & ns \\
\hline LA diameter (cm) & $4.7 \pm 0.8$ & $8.0 \pm 10.5$ & ns \\
\hline $\mathrm{RVdD}(\mathrm{cm})$ & $2.9 \pm 0.4$ & $3.0 \pm 0.6$ & ns \\
\hline LVEdV (ml) & $187.0 \pm 37.0$ & $191.6 \pm 72.9$ & ns \\
\hline $\operatorname{LVs}(\mathrm{ml})$ & $118.9 \pm 41.0$ & $104.0 \pm 41.5$ & ns \\
\hline TEl index & $0.7 \pm 0.2$ & $0.5 \pm 0.4$ & ns \\
\hline $\begin{array}{l}\text { Mitral regurgitation } \\
\mathrm{dP} / \mathrm{dT}(\mathrm{mmHg} / \mathrm{s})\end{array}$ & $569.5 \pm 294.1$ & $392.5 \pm 83.0$ & ns \\
\hline
\end{tabular}

Table 2 Comparison of selected parameters in patients with DCM from group A (atorvastatin group) and group B (without statin) after 5-year follow-up (Continued)

\begin{tabular}{|c|c|c|c|}
\hline \multicolumn{4}{|c|}{ Clinical state of patients } \\
\hline 6-MWT (m) & $419.3 \pm 116.0$ & $376.7 \pm 114.3$ & ns \\
\hline \multicolumn{4}{|c|}{ NYHA class (No. of patients [\%]) } \\
\hline I & $1(5)$ & $3(13)$ & ns \\
\hline$\|$ & $12(54)$ & $10(44)$ & \\
\hline III & $8(36)$ & $7(30)$ & \\
\hline IV & $1(5)$ & $3(13)$ & \\
\hline \multicolumn{4}{|c|}{$\begin{array}{l}{ }^{*} \text { ns - not statistically significant. } \\
\text { ABBREVIATIONS: } 6 M W T \text { 6-minute walk test; } B M I \text { body mass index; } N a \\
\text { sodium; } K \text { potassium; } H D L \text { high-density lipoprotein; } L D L \text { low-density } \\
\text { lipoprotein; } A S P A T \text { aspartate transaminase; } A L A T \text { alanine transaminase; } C R P \\
\text { C-reactive protein; NT-proBNP N-terminal pro-brain natriuretic peptide; TNF } \\
\text { tumor necrosis factor; TGF beta-transforming growth factor beta; GFR MDRD } \\
\text { glomerular filtration rate using modification of diet in renal disease formula; } \\
L V d D \text { left ventricular diastolic diameter; } L V s D \text { left ventricular systolic diameter; } \\
L V E F \text { left ventricular ejection fraction; } L A \text { left atrium; } R V d D \text { right ventricular } \\
\text { diastolic diameter; } L V E d V \text { left ventricular end-diastolic volume; } L V s V \text { left } \\
\text { ventricular systolic volume; } N Y H A ; \text { New York heart association. }\end{array}$} \\
\hline
\end{tabular}

Safety and tolerance of atorvastatin therapy

No patients had symptoms of myopathy. There were no significant changes in aminotransferases activities between investigated groups of patients.

\section{Hospitalization and survival assessment}

The following factors influenced the risk of HF hospitalizations on the basis of single-factor logistic regression: leg edema, hepatomegaly, no beta-blocker therapy, NTproBNP, LVEF, LVsD and result of the 6-MWT (Table 3). On the basis of single-factor logistic regression statistical analysis we found that: no statin therapy, leg edema, hepatomegaly, no beta-blocker therapy, renal failure, rehospitalizations, lower BMI, LVEF, higher NT-proBNP, LVsD, LVdD, MR degree, significantly influenced the risk of death (Table 4).

The survival of patients was $87.7 \%$ (95\%CI: 79.2-96.2\%), 67.9\% (95\%CI: 55.7-80.2\%), and 63.1\% (95\%CI: 50.0 $76.2 \%$ ) after 1, 2, and 5 years, respectively (Figure 1). Based on a comparison of curves using the log-rank test, the probability of survival to 5 years was significantly higher in the group taking a low dose of statin $(p=0.005$; hazard ratio $[\mathrm{HR}] 3.48$; 95\% Cl 1.42-8.56) (Figure 2).

According to the multivariate regression analysis we found that NT-proBNP (odds ratio [OR] 1.00, $p=0.007$ ) and LVdD (OR 2.96, $p=0.025$ ) were the independent risk factors of death, and 6-MWT (OR 0.99, $p=0.001$ ) was the only independent risk factors of re-hospitalization for worsening heart failure. On the basis of ROC curve analysis we found that NT-proBNP values $\geq 1826 \mathrm{pg} / \mathrm{ml}$, LVEF $\leq 30 \%, \mathrm{BMI} \leq 25.5$, and $\mathrm{MR} \geq 1.5$ were significant predictors of both re-hospitalization and increased mortality in this group of patients. 
Table 3 Predictors of re-hospitalizations in single-factor logistic regression

\begin{tabular}{|c|c|c|c|}
\hline Categorical variable & With re-hospitalization (\%) & Without re-hospitalization (\%) & $p$ \\
\hline leg edema & 91 & 9 & 0.009 \\
\hline hepatomegaly & 88 & 11 & 0.03 \\
\hline No beta-blocker therapy & 98 & 0 & 0.006 \\
\hline Quantitative variable & With re-hospitalization (median; Q25-Q75) & Without re-hospitalization (median; Q25-Q75) & $p$ \\
\hline BMI 2* & $25 ; 24-30$ & $30 ; 26-32$ & 0.04 \\
\hline NT-proBNP 1 & $1848 ; 931-3248$ & $895 ; 511-2026$ & 0.02 \\
\hline NT-proBNP 2 & $1852 ; 775-4000$ & $745 ; 360-1680$ & 0.005 \\
\hline LVEF 1 & $27 ; 22-31$ & $33 ; 28-38$ & 0.02 \\
\hline LVEF 2 & $30 ; 24-32$ & $34 ; 29-40$ & 0.02 \\
\hline LVsD 2 & $6 ; 5.2-6.4$ & $5.3 ; 4.4-5.6$ & 0.001 \\
\hline MR 1 & $1.5 ; 1-2$ & $1 ; 0-1$ & 0.03 \\
\hline MR 2 & $1 ; 1-2$ & $1 ; 0-1$ & 0.03 \\
\hline 6-MWT 1 & $350 ; 290-405$ & $438 ; 350-490$ & 0.01 \\
\hline 6-MWT 2 & $370 ; 290-450$ & $480 ; 395-595$ & 0.001 \\
\hline
\end{tabular}

*1 - for variables assessed after inclusion; 2 - for variables assessed after 2 months.

Q25-Q75: quartiles 25\% and 75\%.

ABBREVIATIONS: $B M I$ body mass index; NT-proBNP N-terminal pro-brain natriuretic peptide; $L V E F$ left ventricular ejection fraction; $L V s D$ left ventricular systolic diameter; MR mitral regurgitation; 6 MWT 6 minute walk test.

\section{Discussion}

Statins act by inhibiting the enzyme 3-hydroxy-3methylglutaryl coenzyme A (HMG-CoA) reductase, a key step in the synthesis of cholesterol. The pleiotropic effects of statins may be connected with this basic mechanism. In this mechanism, not only the synthesis of cholesterol is reduced, but also that of the derivatives of mevalonic acid, including isoprenoids. These compounds participate in protein isoprenylation that links lipid fragments with intracellular proteins [23]. In limiting the production of isoprenoids, statins block the function of cytoplasmic regulatory proteins - GTP-ases from the Rho

Table 4 Predictors of death in single-factor logistic regression

\begin{tabular}{|c|c|c|c|}
\hline Categorical variable & Death (\%) & Survival (\%) & $p$ \\
\hline No statin treatment & 78 & 21 & 0.006 \\
\hline Leg edema & 72 & 27 & 0.027 \\
\hline Hepatomegaly & 66 & 33 & 0.009 \\
\hline No beta-blocker therapy & 87.5 & 12.5 & 0.001 \\
\hline Renal failure & 80 & 20 & 0.025 \\
\hline Re-hospitalizations & 81 & 18 & 0.001 \\
\hline Quantitative variable & With death (median; Q25-Q75) & Without death (median; Q25-Q75) & $p$ \\
\hline BMI 1 & $24 ; 24-26$ & $30 ; 25-32$ & 0.002 \\
\hline BMI 2 & $24 ; 23-26$ & $30 ; 25-32$ & 0.003 \\
\hline NT-proBNP $1^{*}$ & $2771 ; 1500-5013$ & $980 ; 500-2130$ & 0.001 \\
\hline NT-proBNP 2 & 2900; 1296-4421 & $766 ; 470-1680$ & 0.001 \\
\hline LVEF 1 & $27 ; 21-29$ & $32 ; 26-38$ & 0.01 \\
\hline LVEF 2 & $30 ; 22-31$ & $32 ; 28-40$ & 0.03 \\
\hline LVsD 2 & $6.2 ; 5.3-6.7$ & $5.3 ; 4.5-5.9$ & 0.01 \\
\hline LVdD 2 & $7.6 ; 6.7-8.4$ & $6.6 ; 6.0-7.2$ & 0.003 \\
\hline MR 1 & $2 ; 1-3$ & $1 ; 0-1$ & 0.001 \\
\hline MR 2 & $2 ; 1-3$ & $1 ; 0-1$ & 0.001 \\
\hline
\end{tabular}

*1 - for variables assessed after inclusion; 2 - for variables assessed after 2 months.

Q25-Q75: quartiles 25\% and 75\%.

ABBREVIATIONS: $B M I$ body mass index; NT-proBNP N-terminal pro-brain natriuretic peptide; LVEF left ventricular ejection fraction; $L V s D$ left ventricular systolic diameter; $L V d D$ left ventricular diastolic diameter; $M R$ mitral regurgitation. 


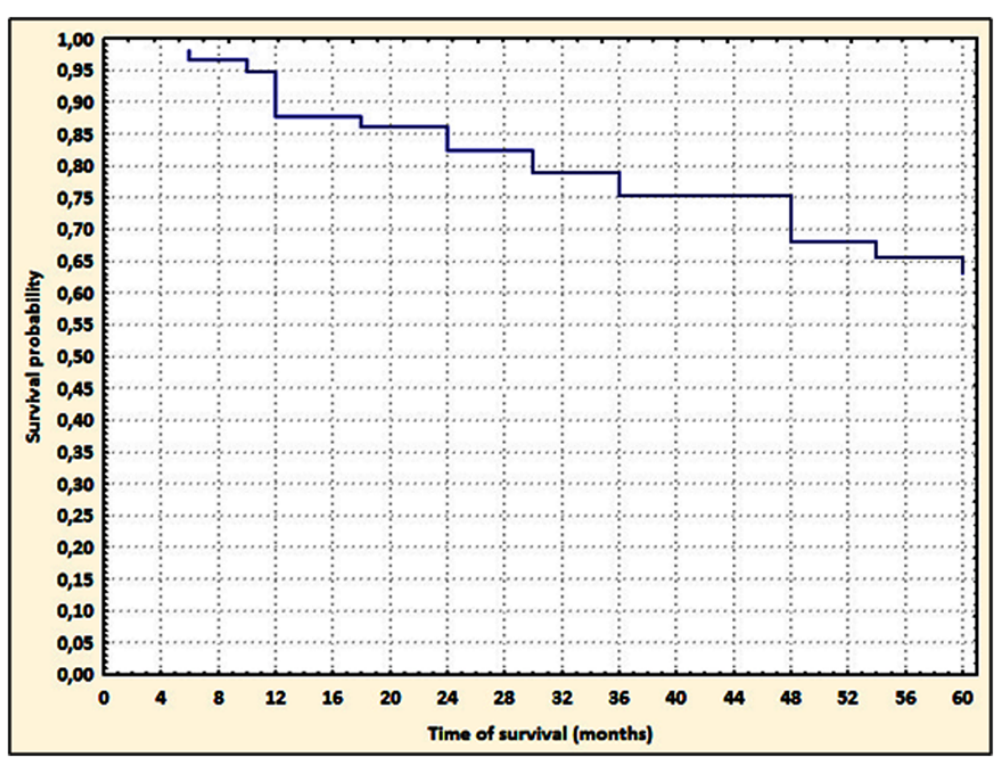

Figure 1 Kaplan-Meier curves probability of survival in patients with DCM after 5-year follow-up. *DCM - dilated cardiomyopathy.

protein family, such as Ras, Rac1 and Rap. This results in increased angiogenesis and myocardial perfusion, decreased myocardial apoptosis, and improvement in endothelial and cardiac function [24]. The deteriorating circulatory insufficiency is characterized by an increased amount of free radicals, which may inactivate nitric oxide (NO) [25,26]. Therefore, additional advantages of Rho protein inhibition are also connected with increased endothelial synthesis of NO and reduced expression of endothelin-1, which has a positive effect on endothelial function $[25,26]$. In addition, statins inhibit the synthesis of inflammatory cytokines and chemokines, improve autonomic function, and reverse myocardial remodeling $[27,28]$.

Because of the pleiotropic effect of statins, there have been attempts to use these drugs in the treatment of DCM of nonischemic etiology. The present prospective, randomized study evaluated the effects of a small atorvastatin dose in 5-year observation on the parameters of inflammation, left ventricular function, hospitalizations and mortality in CHF patients with DCM who have already received standard HF therapy. In the atorvastatin group compared with the group without statin IL-6 and

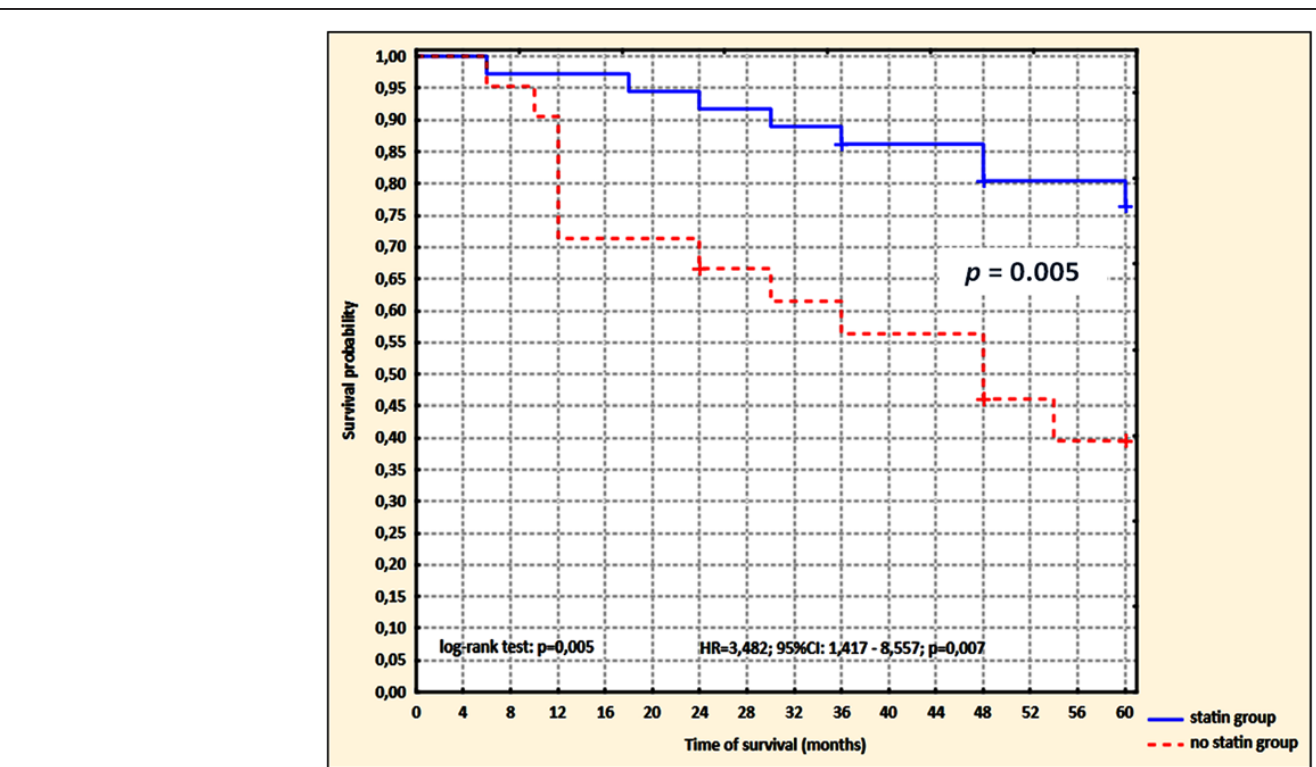

Figure 2 Probability of 5-year survival in patients with DCM treated and not treated with atorvastatin using Kaplan-Meier method. 
TNF- $\alpha$ concentrations were considerably lower. Also, UA concentration was lower in the atorvastatin group than in the group without statin therapy. No significant differences concerning NT-proBNP concentration, echocardiographic parameters of the left ventricle, distance in the 6-min walk test and in functional classification according to NYHA were observed between the examined groups. In the statin group after 5 years a decrease in NT-proBNP concentration compared with initial values and a decrease in LVdD and LVsD were achieved. LVEF significantly increased also in the atorvastatin group. Based on a comparison of curves using the logrank test, the probability of survival to 5 years is higher in the group receiving a low dose of atorvastatin.

According to studies, hyperuricemia is an independent prognostic marker in chronic and in acute heart failure (AHF) [29,30]. Hyperuricemia can produce additional adverse effects on the cardiovascular system and can mediate the immune response $[31,32]$. Hyperuricemia in patients with heart failure is associated with higher levels of serum markers of inflammation (C-reactive protein [CRP], IL-6, and neutrophil count) [33] and higher levels of markers of endothelial activation, such as the soluble intercellular adhesion molecule-1, and inflammatory markers such as IL-6, TNF- $\alpha$, and its receptors [34,35]. Although UA level has been associated with an increased risk of cardiovascular events, it is unclear whether UA can provide greater prognostic information than NTproBNP in advanced HF with nonischemic DCM. In the study of Kim et al. UA and NT-proBNP values were obtained from 122 DCM patients. Development of clinical events during follow-up was defined as the composite of cardiac death and readmission for heart failure. During follow-up UA and NT-proBNP values were significantly higher in patients with events. On multivariate analysis, UA remained the only independent predictor of prognosis [35]. The authors' findings demonstrated that UA value could be an informative predictor in nonischemic DCM. In our study we observed lower UA concentration in the group treated with atorvastatin, which perhaps may be connected with better prognosis in these patients. In DCM, an immunological component may play a role, so immunomodulatory effects of statins may be more advantageous. The study of Wojnicz et al. [36] evaluated the safety, tolerability, and efficacy of statin therapy in patients with heart failure secondary to inflammatory DCM and moderately elevated low-density lipoprotein cholesterol levels. Seventy-four patients were randomized to receive atorvastatin or conventional treatment for HF. After 6 months of therapy, the predefined primary efficacy end point (an increase of $>5 \%$ in the absolute left ventricular ejection fraction and $\geq 2$ selected criteria by echocardiography and a decrease in NYHA functional class) was significant in the statin-treated patients $(p=0.004)$. Among secondary efficacy parameters, the quality-of-life index showed a trend suggesting the benefit of statin therapy. These results suggest a positive anti-inflammatory effect of atorvastatin in patients with DCM. In the research of Gurguna et al. [37], the effectiveness of 12 weeks' therapy with fluvastatin, $80 \mathrm{mg} /$ day, was assessed concerning the concentration of inflammatory cytokines and LV function in patients with cardiac insufficiency and DCM as well as with cardiac insufficiency caused by coronary thrombosis. In both groups, a considerable improvement of ventricular function and clinical symptoms of cardiac insufficiency was achieved, as well as a decrease in the concentration of IL-6 and TNF-alpha [37]. In the study by Horwicha et al. [38], statin therapy was related to a higher survival rate without the necessity of urgent transplant in patients with cardiac insufficiency of ischemic origin as well as of non-ischaemic origin (91 vs 72\%, $p<0.001$ and 81 vs $63 \%, p<0.001$, respectively) [38]. Sola et al. [39] evaluated the influence of atorvastatin $(20 \mathrm{mg} /$ day $)$ on vascular indicators of inflammation and echocardiographic indicators in 89 patients with dilated cardiomyopathy of nonischemic origin in NYHA class II to IV, with LVEF $<35 \%$. In the group treated with atorvastatin, considerable reduction of end diastolic and end systolic volume of the LV was obtained compared with the group treated with placebo [39]. In the statin group they observed higher LVEF and a considerable decrease in the concentration of hsCRP, TNF- $\alpha$ receptor 2 , and IL-6, together with an increase of superoxide dismutase (E-SOD) activity in erythrocytes, which meant that oxidative stress and the inflammatory process decreased significantly within the 12-month observation. A significant improvement of clinical condition of patients in the atorvastatin group was also observed (NYHA class in this group $2.2 \pm 0.3$ compared with $2.9 \pm 0.3$ in the placebo group, $p=0.001$ ) [39]. In the study by Node et al. [40], 53 patients with symptomatic DCM of nonischemic origin (NYHA class II and III) with LVEF $<40 \%$ were assigned to a group receiving $10 \mathrm{mg}$ of simvastatin or to a placebo group for 14 weeks. Patients treated with statin had considerably lower functional class according to NYHA and higher LVEF compared with patients from the placebo group. The concentrations of TNF-alpha, IL- 6 and BNP were also significantly lower in the simvastatin group. The results of our study showing decreased IL- 6 and TNF- $\alpha$ concentrations are in accord with Gurguna et al. [37], Horwich et al.[38], Sola et al. [39] and Node et al. [40]. We also observed a decrease in NT-proBNP concentration compared to initial values and a decrease in LVdD and LVsD in the group treated with atorvastatin.

On the other hand, Bleske et al. [41] randomly assigned 15 patients with DCM of nonischemic origin in functional class I to III according to NYHA to a group treated with 
$80 \mathrm{mg}$ of atorvastatin or to a placebo group for 12 weeks. Although treatment was found to be safe and associated with considerable reduction of LDL cholesterol, the authors did not observe a significant difference between atorvastatin and placebo concerning NT-proBNP, hsCRP, TNF-alpha and indicators of endothelial activation: vascular adhesion molecule-1, intracellular adhesive molecule-1 and Pselectin [41]. In the study carried out by Krum et al. [42], the influence of rosuvastatin $40 \mathrm{mg}$ in 86 patients with systolic heart failure (LVEF $<40 \%$ ) of ischemic or nonischemic etiology was assessed (68 patients with DCM). The primary end point was change in LVEF by radionuclide ventriculogram. Secondary end points included changes in echocardiographic parameters, neurohormonal and inflammatory markers, Packer composite score, death and HF hospitalization. Despite being safe and effective at decreasing plasma cholesterol, high-dose rosuvastatin did not beneficially alter parameters of LV remodeling [42].

In our study we observed better survival in the atorvastatin group of patients with DCM. The UNIVERSE and CORONA studies using rosuvastatin showed no beneficial effect on mortality in patients with mainly ischemic chronic HF [11,12]. In the post-hoc analysis of the Eplerenone Post-Acute Myocardial Infarction Heart Failure Efficacy and Survival Study (EPHESUS) [43], the initiation of statin therapy mainly during hospital stay for acute HF complicating acute myocardial infarction was associated with a lower risk of all-cause death. In a post-hoc analysis performed in 6632 patients included in the EPHESUS trial, $47 \%$ of patients had a statin prescribed at baseline. During a mean follow-up of $16 \pm 7$ months, all-cause death occurred in $12 \%$ of patients taking and in $18 \%$ of patients not taking a statin $(p<0.001)$. The risk of all-cause death was $20 \%$ lower in patients on statin. The reduction of all-cause death appears to be mainly attributable to a lower rate of cardiovascular death, especially sudden death and stroke [43].

The GISSI-HF trial [13] is the only large prospective study with some relevance to DCM because rosuvastatin was examined in a mixed population with heart failure. Rosuvastatin $10 \mathrm{mg} /$ day did not affect clinical outcomes (death, hospitalization for cardiovascular reasons) in patients with $\mathrm{CHF}$ of any cause. However, the number of patients with DCM was small [13]. Treatment with rosuvastatin was safe [13]

To determine whether statin therapy improves survival in patients with heart failure secondary to nonischemic DCM, data from 1024 patients (NYHA functional class III and IV) with LVEF $\leq 0.35$, who were enrolled in the BEST (Beta-blocker Evaluation of Survival Trial) trial were analyzed $[44,45]$. Statin therapy was independently associated with decreased all-cause mortality (HR 0.38, 95\%CI 0.18-0.82, $p=0.0134$ ) and cardiovascular death (HR 0.42, 95\%CI 0.18-0.95, $p=0.037$ ) [45]. Sudden deaths due to rapid ventricular arrhythmias account for $\sim 50-80 \%$ of all deaths in patients with idiopathic DCM. This reduction of deaths might be caused, in part, by a reduction in arrhythmic sudden death $[46,47]$. Confirmation of this thesis can be found in the study by Xian-Zhi et al. [48], where early and intensive atorvastatin therapy significantly decreased the recurrence of ventricular premature beat or non-sustained ventricular tachycardia.

The study by Buber et al. [49] was performed in a subset of 821participants in the Multicenter Automatic Defibrillator Implantation Trial with Cardiac Resynchronization Therapy (MADIT-CRT) trial with a diagnosis of heart failure other than ischemic. In this analysis of data covering 821 patients, 499 of them received statins. Multivariate analysis showed that time-dependent statin therapy was independently associated with a significant $77 \%$ reduction in the risk of fast ventricular tachyarrhythmias (VT/VF) or death $(p<0.001)$ and with a significant $46 \%$ reduction in the risk of appropriate implantable cardioverter defibrillator shocks $(p=0.01)$. Consistent with these findings, the cumulative probability of fast VT/VF or death at 4 years of follow-up was significantly lower among patients who were treated with statins (11\%) as compared with study patients who were not treated with statins $(19 \% ; p=0.006$ for the overall difference during follow-up). The study demonstrated that the use of statins is associated with a significant reduction in life-threatening arrhythmias in patients with nonischemic heart failure [49].

One of the potential explanations why recent prospective studies using hydrophilic rosuvastatin have not shown any beneficial effect on mortality [13,50-52] may be connected with the observation that metabolic and cardiac effects may differ between the lipophilic and hydrophilic statins. It may be suggested that one of the beneficial mechanisms of statins could be to rapidly affect signaling pathways in cell membranes of the myocardium and/or the autonomic nervous system, thereby protecting patients from life-threatening arrhythmias. This assumption would be in line with data showing statins to improve autonomic neural control and increase electrical stability of the myocardium [13,48-52]. The highly lipophilic statins such atorvastatin and simvastatin become easily embedded into the membrane, having overlapping locations in the hydrocarbon core adjacent to the phospholipid head groups [48]. Gao et al. reported that lipophilic simvastatin therapy in pacing-induced CHF inhibited NADPH oxidative activity in the rostral ventrolateral medulla and reduced the central sympathoexcitatory response in association with improvement in LV function [53]. Activation of the sympathetic nerve system is one of the important prognostic predictors for CHF patients [54]. Tsutamoto et al. randomized 63 stable outpatients with DCM to atorvastatin $(n=32)$ or rosuvastatin $(n=31)$ therapy. They evaluated 
cardiac sympathetic nerve activity by cardiac 123I-metaio dobenzylguanidine (MIBG) scintigraphy, hemodynamic parameters and neurohumoral factors before and after 6 months of treatment [55].

The level of plasma oxidized LDL (oxLDL), a biomarker of oxidative stress in the failing heart, is an independent prognostic predictor in CHF patients [56]. The clinical studies suggested that lipophilic statins improve cardiac sympathetic activity by reducing oxidative stress $[57,58]$. Mason et al. reported that the antioxidant effects of an active metabolite of atorvastatin were stronger than those of rosuvastatin [59]. Therefore, the increase in LVEF observed in the atorvastatin group may be partly related to an improvement of the oxidative stress in the myocardium. Li et al. [60] explored the effect of early statin therapy (atorvastatin and simvastatin) on mortality in patients with nonischemic DCM. A total of 315 patients with nonischemic DCM were enrolled. The median follow-up period was 45.1 months. By single-factor analysis, they found that the follow-up mortality was $17 \%$ in the statin group and it was significantly lower than the $37 \%$ mortality of non-statin users $(p=0.003)$; in patients with worsening cardiac function NYHA III-IV, the mortality of the statin group was $17 \%$ while a much higher mortality of $47 \%$ was found in non-statin users $(p=0.003)$. The authors concluded that early treatment with atorvastatin or simvastatin was closely correlated with the reduction of mortality in nonischemic dilated cardiomyopathy patients, which is consistent with our findings [60-62]. Our findings of better survival in the atorvastatin group are consistent with Vrtovec et al. [14], Domanski et al. [45] and Li et al. [60] and may support the underlying mechanism described by Buber et al. [49] and Tsutamoto et al. [55].

Our study has several limitations that include the relatively small number of patients at 5-year follow-up. The dose of statin after 2-month therapy in the atorvastatin group was adjusted individually to 10 or $20 \mathrm{mg}$. The open-trial methodology (not double-blinded study) need to be considered as a study limitation.

In conclusion, the pleiotropic effects of atorvastatin in a small dose (10-20 mg/day) significantly reduce levels of inflammatory cytokines (TNF- $\alpha$, IL-6) and uric acid, as well as improve hemodynamic parameters (LVdD, LVsD and LVEF) in DCM patients after 5 years of treatment, and have a significant impact on the survival of this group of patients.

\section{Competing interests}

The authors declared that they have no competing interests.

\section{Authors' contributions}

ABD planned the study protocol, took care about the patients and coordinate the research, DPM drafted the manuscript and revised it critically for important intellectual content, MR took part in the data analysis and drafted the manuscript, $\mathrm{SvH}$ took part in the data analysis and drafted the manuscript, JR drafted the manuscript, MB conceived of the study, participated in its design, and coordination, and prepared the final version of the manuscript. All authors read and approved the final manuscript.

\section{Acknowledgment}

We would like to kindly thank to Professor Stefan D. Anker (Charité Hospital, Berlin, Germany) for his substantial suggestions on this paper. The study was financed from a JUVENTUS PLUS grant 2011 (No. IP2010002770) of the Polish Ministry of Science and Higher Education.

\section{Author details}

${ }^{1}$ Department of Hypertension, Chair of Nephrology and Hypertension, Medical University of Lodz, Lodz, Poland. 'Department of Clinical Biochemistry, Royal Free Campus, University College London Medical School, University College London (UCL), London, UK. ${ }^{3}$ BioMedical Department of Internal Medicine and Medical Specialties, University of Palermo, Palermo, Italy. ${ }^{4}$ Euro-Mediterranean Institute of Science and Technology, Palermo, Italy. ${ }^{5}$ Applied Cachexia Research, Department of Cardiology, Charité Medical School, Campus Virchow-Klinikum, Berlin, Germany. 'Department of Nephrology, Hypertension and Family Medicine, Chair of Nephrology and Hypertension, Medical University of Lodz, Lodz, Poland.

Received: 23 March 2013 Accepted: 31 March 2013

Published: 8 April 2013

\section{References}

1. Kaski JP, Elliott P, ESC Working Group: The classification concept of the ESC Working Group on myocardial and pericardial diseases for dilated cardiomyopathy. Herz 2007, 32(6):446-451.

2. Bielecka-Dabrowa A, Mikhailidis DP, Hannam S, Aronow WS, Rysz J, Banach M: Statins and dilated cardiomyopathy: do we have enough data? Expert Opin Investig Drugs 2011, 20(3):315-323.

3. Maisch B, Richter A, Sandmöller A, Portig I, Pankuweit S: BMBF-Heart Failure Network. Inflammatory dilated cardiomyopathy (DCMI). Herz 2005, 30(6):535-544.

4. Bielecka-Dabrowa A, Wierzbicka M, Goch JH: Proinflammatory cytokines in cardiovascular diseases as potential therapeutic target. Wiad Lek 2007, 60(9-10):433-438

5. Bielecka-Dabrowa A, Von Haehling S, Aronow WS, Ahmed MI, Rysz J, Banach M: Heart failure biomarkers in patients with dilated cardiomyopathy. Int J Cardiol 2013. doi:10.1016/j.ijcard.2013.01.157.

6. Gluba A, Bielecka-Dabrowa A, Mikhailidis DP, Wong ND, Franklin SS, Rysz J, Banach M: An update on biomarkers of heart failure in hypertensive patients. J Hypertens 2012, 30(9):1681-1689.

7. Martin J, Denver R, Bailey M, Krum H: In vitro inhibitory effects of atorvastatin on cardiac fibroblasts: implications for ventricular remodeling. Clin Exp Pharmacol Physiol 2005, 32:697-701.

8. Zimmermann AV, Doehner W, Vaz Pérez A, Schmidt H, Volk HD, Anker SD, Rauchhaus M: The relationship between high-density lipoprotein, bacterial lipopolysaccharide, and tumour necrosis factor-a in patients with acute decompensated heart failure. Arch Med Sci 2008, 4:380-385.

9. Haendeler J, Hoffmann J, Zeiher AM, Dimmeler S: Antioxidant effects of statins via S-nitrosylation and activation of thioredoxin in endothelial cells. Circulation 2004, 110:851-861.

10. Kowalski J, Barylski M, Banach M, Grycewicz J, Irzmański R, Pawlicki L: Neutrophil superoxide anion generation during atorvastatin and fluvastatin therapy used in coronary heart disease primary prevention. J Cardiovasc Pharmacol 2006, 48(4):143-147.

11. Ashton E, Windebank E, Skiba M, Reid C, Schneider H, Rosenfeldt F, Tonkin A, Krum $\mathrm{H}$ : Why did high-dose rosuvastatin not improve cardiac remodeling in chronic heart failure? Mechanistic insights from the UNIVERSE study. Int J Cardiol 2011, 146(3):404-407.

12. Kjekshus J, Apetrei A, Barrios V, et al: and for the CORONA Group. Rosuvastatin in older patients with systolic heart failure. N Engl J Med 2007, 357:2248-2261.

13. Tavazzi L, Maggioni AP, Marchioli R, et al: Gissi-HF Investigators. Effect of rosuvastatin in patients with chronic heart failure (the GISSI-HF trial): a randomised, double-blind, placebo-controlled trial. Lancet 2008, 372:1231-1239.

14. Vrtovec B, Okrajsek R, Golicnik A, Ferjan M, Starc V, Schlegel TT, et al: Atorvastatin therapy may reduce the incidence of sudden cardiac death 
in patients with advanced chronic heart failure. J Cardiac Fail 2008, 14:140-144

15. Correale M, Brunetti ND, Totaro A, Montrone D, Russo AR, Fanigliulo AM, leva R, Di Biase M: Statin therapy blunts inflammatory activation and improves prognosis and left ventricular performance assessed by Tissue Doppler Imaging in subjects with chronic ischemic heart failure: results from the Daunia Heart Failure Registry. Clinics (Sao Paulo) 2011, 66(5):777-784.

16. Bielecka-Dabrowa A, Goch JH, Mikhailidis DP, Rysz J, Maciejewski M, Banach $M$ : The influence of atorvastatin on parameters of inflammation and function of the left ventricle in patients with dilated cardiomyopathy. Med Sci Monit 2009, 15(12):MS12-MS23.

17. Dickens K, Cohen-Solal A, Filippatos G, et al: ESC guidelines for the diagnosis and treatment of acute and chronic heart failure 2008: the Task Force for the diagnosis and treatment of acute and chronic heart failure 2008 of the European Society of Cardiology. Eur J Heart Fail 2008, 10:933-989.

18. Elliott $P$, Andersson B, Arbustini E, Bilinska Z, Cecchi F, Charron P, Dubourg O, Kühl U, Maisch B, McKenna WJ, Monserrat L, Pankuweit S, Rapezzi C, Seferovic P, Tavazzi L, Keren A: Classification of the cardiomyopathies: a position statement from the European society of cardiology working group on myocardial and pericardial diseases. Eur Heart J 2008, 29:270-276.

19. Bielecka-Dabrowa A, Wierzbicka M, Dabrowa M, Goch A: New methods in laboratory diagnostics of dilated cardiomyopathy. Cardiol J 2008, 15(4):388-395.

20. Faigenbaum H, Armstrong WF, Ryan T: Echokardiografia Faigenbauma" Wydanie polskie. Warszawa: Medipage; 2006:238-239. in Polish

21. ESC Guidelines for the diagnosis and treatment of acute and chronic heart failure 2012: The Task Force for the Diagnosis and Treatment of Acute and Chronic Heart Failure2012 of the European Society of Cardiology: Developed in collaboration with the Heart Failure Association (HFA) of the ESC. Eur Heart J 2012, 33(14):1787-1847.

22. Bargiggia GS, Bertucci C, Recusani F, et al: A new method for estimating left ventricular $\mathrm{dP} / \mathrm{dT}$ by continuous wale Doppler - echocardiography. Validation studies at cardiac catheterization. Circulation 1989, 80:1287-1292.

23. Wassmann $\mathrm{S}$, Laufs $U$, Baumer AT, et al: Inhibition of geranylgeranylation reduces angiotensin II-mediated free radical production in vascular smooth muscle cells: involvement of angiotensin AT1 receptor expression and Rac1 GTPase. Mol Pharmacol 2001, 59:646-654.

24. Yoon SJ, Yoon YW, Lee BK, et al: Potential role of HMG CoA reductase inhibitor on oxidative stress induced by advanced glycation endproducts in vascular smooth muscle cells of diabetic vasculopathy. Exp Mol Med 2009, 41:802-811.

25. Laufs U, La Fata V, Plutzky J: Upregulation of endothelial nitric oxide synthase by HMG CoA reductase inhibitors. Circulation 1998, 97:1129-1135

26. Tousoulis D, Antoniades C, Bosinakou E, et al: Effects of atorvastatin on reactive hyperaemia and the thrombosis-fibrinolysis system in patients with heart failure. Heart 2005, 91:27-31.

27. Banach M, Mikhailidis DP, Kjeldsen SE, Rysz J: Time for new indications for statins? Med Sci Monit 2009, 15(12):MS1-MS5.

28. Banach M, Drozdz J, Okonski P, Rysz J: Immunological aspects of the statins' function in patients with heart failure: a report from the Annual Conference of ESC - Heart Failure 2005. Cell Mol Immunol 2005, 2(6):433-437.

29. Anker SD, Coats AJS: Metabolic, functional, and hemodynamic staging for CHF? Lancet 1996, 348:1530.

30. Anker SD, Doehner W, Rauchhaus M, et al: Uric acid and Survival in Chronic Heart Failure: Validation and Application in Metabolic, Functional, and Hemodynamic Staging. Circulation 2003, 107:1991-1997.

31. Niesiu A, Campeanu A, Dusceac D: Serum uric acid and cardiovascular disease. J Clin Med 2010, 5(3):186-192.

32. Lippi G, Mantagna M, Franchini M, et al: The paradoxical relationship between serum acid uric and cardiovascular disease. Clin Chim Acta 2008, 392:1-7

33. Kanellis J, Kang DH: Uric acid as a mediator of endothelial dysfunction, inflammation, and vascular disease. Semin Nephrol 2005, 25:39-42.

34. Leyva F, Anker SD, Godsland IF, Teixeira M, Hellewell PG, Kox WJ, PooleWilson PA, Coats AJ: Uric acid in chronic heart failure: a marker of chronic inflammation. Eur Heart J 1998, 19:1814-1822.

35. Kim H, Shin HW, Son J, Yoon HJ, Park HS, Cho YK, Han CD, Nam CW, Hur $\mathrm{SH}$, Kim YN, Kim KB: Uric Acid as prognostic marker in advanced nonischemic dilated cardiomyopathy: comparison with N-terminal pro B-type natriuretic peptide level. Congest Heart Fail 2010, 16(4):153-158.
36. Wojnicz R, Wilczek K, Nowalany-Kozielska E, Szyguła-Jurkiewicz B, Nowak J, Poloński L, Dyrbuś K, Badziński A, Mercik G, Zembala M, Wodniecki J, Rozek MM: Usefulness of atorvastatin in patients with heart failure due to inflammatory dilated cardiomyopathy and elevated cholesterol levels. Am J Cardio/ 2006, 97(6):899-904.

37. Gurguna $C$, Ildizli $M$, Yavuzgil $O$, et al: The effects of short term statin treatment on left ventricular function and inflammatory markers in patients with chronic heart failure. Int J Cardiol 2008, 123:102-107.

38. Horwich TB, MacLellan WR, Fonarow GC: Statin therapy is associated with improved survival in ischemic and nonischemic heart failure. J Am Coll Cardiol 2004, 43:642-648.

39. Sola S, Mir MQ, Lerakis S, et al: Atorvastatin improves left ventricular systolic function and serum markers of inflammation in nonischemic heart failure. J Am Coll Cardiol 2006, 47:332-337.

40. Node K, Fujita M, Kitakaze M, et al: Short-term statin therapy improves cardiac function and symptoms in patients with idiopathic dilated cardiomyopathy. Circulation 2003, 108:839-843.

41. Bleske BE, Nicklas JM, Bard RL, et al: Neutral effect on markers of heart failure, inflammation, endothelial activation and function, and vagal tone following high-dose HMG-CoA reductase inhibition in non-diabetic patients with non-ischemic cardiomyopathy and average low-density lipoprotein level. J Am Coll Cardiol 2006, 47:338-341.

42. Krum H, Ashton E, Reid C, et al: Double-blind, randomized, placebo-controlled study of high-dose HMG CoA reductase inhibitor therapy on ventricular remodeling, pro-inflammatory cytokines and neurohormonal parameters in patients with chronic systolic heart failure. J Card Fail 2007, 13:1-7.

43. Dobre D, Rossignol P, Murin J, Parkhomenko A, Lamiral Z, Krum H, Van Veldhuisen DJ, Pitt B, Zannad F: Statin therapy and clinical outcomes in myocardial infarction patients complicated by acute heart failure: insights from the EPHESUS trial. Eur J Heart Fail 2013, 15(2):221-227.

44. Desai RV, Banach M, Ahmed MI, Mujib M, Aban I, Love TE, White M, Fonarow G, Deedwania P, Aronow WS, Ahmed A: Impact of baseline systolic blood pressure on long-term outcomes in patients with advanced chronic systolic heart failure (insights from the BEST trial). Am J Cardio/ 2010, 106(2):221-227.

45. Domanski M, Coady S, Fleg J, et al: Effect of statin therapy on survival in patients with nonischemic dilated cardiomyopathy (from the Beta- blocker Evaluation of Survival Trial [BEST]). Am J Cardiol 2007, 99:1448-1450

46. Roberts WC, Siegel RJ, McManus BM: Idiopathic dilated cardiomyopathy: analysis of 152 necropsy patients. Am J Cardiol 1987, 60:1340-1355.

47. De Sutter J, Tavernier R, De Buyzere $M$, et al: Lipid lowering drugs and recurrences of life-threatening ventricular arrhythmias in high-risk patients. J Am Coll Cardiol 2000, 36:766-772.

48. Xian-zhi $H$, Sheng-hua $Z$, Xin-hong $W$, et al: The effect of early and intensive statin therapy on ventricular premature beat or non-sustained ventricular tachycardia in patients with acute coronary syndrome. Cardiol J 2010, 17(4):381-385.

49. Buber J, Goldenberg I, Moss AJ, et al: Reduction in Life-Threatening Ventricular Tachyarrhythmias in Statin-Treated Patients With Nonischemic Cardiomyopathy Enrolled in the MADIT-CRT (Multicenter Automatic Defibrillator Implantation Trial with Cardiac Resynchronization Therapy). J Am Coll Cardiol 2012, 60(8):749-755.

50. Kjekshus J, Apetrei E, Barrios V, Bohm M, Cleland JG, Cornel JH, et al: Rosuvastatin in older patients with systolic heart failure. $N$ Engl J Med 2007, 357:2248-2261.

51. Aydin U, Ugurlucan M, Gungor F, Ziyade S, Inan B, Banach M, Kalko Y, Yasar T: Effects of atorvastatin on vascular intimal hyperplasia: an experimental rodent model. Angiology 2009, 60(3):370-377.

52. Xu M, Yuan G, Wei F: Effect of atorvastatin in patients with chronic heart failure - insights from randomized clinical trials. Arch Med Sci 2010, 6(6):866-873.

53. Gao L, Wang W, Li YL, Schultz HD, Liu D, Cornish KG, et al: Simvastatin therapy normalizes sympathetic neural control in experimental heart failure: Roles of angiotensin II type 1 receptors and $\mathrm{NAD}(\mathrm{P}) \mathrm{H}$ oxidase. Circulation 2005, 112:1763-1770.

54. Cohn JN, Levine TB, Olivari MT, Garberg V, Lura D, Francis GS, et al: Plasma norepinephrine as a guide to prognosis in patients with chronic congestive heart failure. N Engl J Med 1984, 311:819-823.

55. Tsutamoto T, Sakai H, Ibe K, Yamaji M, Kawahara C, Nakae I, Fujii M, Yamamoto T, Horie M: Effect of Atorvastatin vs. Rosuvastatin on Cardiac 
Sympathetic Nerve Activity in Non-Diabetic Patients With Dilated Cardiomyopathy. Circ J 2011, 75:2160-2166.

56. Tsutsui T, Tsutamoto T, Wada A, Maeda K, Mabuchi N, Hayashi M, et al: Plasma oxidized low-density lipoprotein as a prognostic predictor in patients with chronic congestive heart failure. J Am Coll Cardiol 2002, 39:957-962.

57. Gomes ME, Lenders JW, Bellersen L, Verheugt FW, Smits P, Tack CJ: Sympathoinhibitory effect of statins in chronic heart failure. Clin Auton Res 2010, 20:73-78.

58. Gomes ME, Tack CJ, Verheugt FW, Smits P, Lenders JW: Sympathoinhibition by atorvastatin in hypertensive patients. Circ J 2010, 74:2622-2626.

59. Mason RP, Walter MF, Day CA, Jacob RF: Active metabolite of atorvastatin inhibits membrane cholesterol domain formation by an antioxidant mechanism. J Biol Chem 2006, 281:9337-9345.

60. Bielecka-Dabrowa A, Goch JH, Rysz J, Maciejewski M, Desai R, Aronow WS, Banach M: Influence of co-existing atrial fibrillation on the efficacy of atorvastatin treatment in patients with dilated cardiomyopathy: a pilot study. Lipids Health Dis 2010, 9:21.

61. Barylski M, Małyszko J, Rysz J, Myśliwiec M, Banach M: Lipids, blood pressure, kidney - what was new in 2011? Arch Med Sci 2011, 7(6):1055-1066.

62. Li X, Liu XP, Liu XH, Du X, Kang JP, Lü Q, Wang HY, Xu X, Liang C, Yan Q, Lei T, Geng LL, Liu BQ, Ma CS: Effect of statin therapy on mortality in patients with non-ischemic dilated cardiomyopathy. Zhonghua Yi Xue Za Zhi 2010, 90(28):1974-1977.

doi:10.1186/1476-511X-12-47

Cite this article as: Bielecka-Dabrowa et al:: The influence of atorvastatin on parameters of inflammation left ventricular function, hospitalizations and mortality in patients with dilated cardiomyopathy - 5-year followup. Lipids in Health and Disease 2013 12:47.

\section{Submit your next manuscript to BioMed Central and take full advantage of:}

- Convenient online submission

- Thorough peer review

- No space constraints or color figure charges

- Immediate publication on acceptance

- Inclusion in PubMed, CAS, Scopus and Google Scholar

- Research which is freely available for redistribution 